Aggression in Amhara Society 'by Mr. R. A. Reminick; ' Sociological Research in Ethiopia ' by Dr. R. Brown; and 'Research in Ethiopian Philosophy' by Professor Claude Sumner.

R. P.

Ethiopian Studies in the U.S.A.

ThE Inter-University Committee for Ethiopian Studies, representing Northwestern University, the University of Chicago, and the University of Illinois, Circle Campus, was formed in I 967 to co-ordinate a programme of graduate education with a focus on Ethiopia, in cooperation with Haile Sellassie I University, Addis Ababa, Ethiopia. Instruction and research in the language, history, culture, institutions, and political development of Ethiopia will be offered during the $1968-9$ academic year by all the co-operating institutions. Students will be able to pursue these studies within the framework of their academic discipline at any of these universities which have specialists on one or more aspects of Ethiopian culture and society. Training in Ethiopian politics, linguistics, and the teaching of Amharic will be provided by Northwestern University; Ethiopian sociology by the University of Chicago; Ethiopian history and anthropology by the University of Illinois, Circle Campus. Students enrolled in any of the three institutions will be able to take advantage of the offerings at all the others. A variety of fellowships and assistantships have been awarded and student and faculty exchanges between Ethiopia and the U.S. are being arranged. The field work of American graduate students in Ethiopia will be facilitated through the good offices of Haile Sellassie I University and through collaboration with its Institute of Ethiopian Studies in Addis Ababa. All inquiries should be addressed to Inter-University Committee for Ethiopian Studies, 18 I3 Hinman Avenue, Evanston, Illinois 60201.

\title{
The African Adult Education Association
}

Trrs Association, formerly the Adult Education Association of East and Central Africa, changed its name, at a conference held in January 1968, to enable it to include professional adult education workers in other parts of Africa. At present it has members from ten African countries. Seven of these were represented at the Conference, on the theme of Continuing Literacy, which was held at Makerere University College, Uganda, and financed by the Dag Hammarskjöld Foundation. A new Constitution for the Association was adopted, and its objects include the arranging of study conferences, residential courses and groups, lectures, seminars, classes, and exhibitions on subjects affecting the citizen, and the publication of reports of educational activities and special studies of the Association and similar bodies. The Association produces a bi-annual journal, African Adult Education (see Africa, xxxviii, 1968, p. 8I), published by the Pergamon Press, Oxford; individual members from outside Africa are accepted (annual subscription: the equivalent of $\$ 4.00$ U.S.). The Secretary of the Association is Miss Lalage Bown, Director of Extra-Mural Studies, University of Zambia, P.O. Box 2379, Lusaka, Zambia.

\section{'Zuka': A Journal of East African Creative Writing}

THE first issue of Zuka (a Swahili word meaning 'emerge') appeared in September 1967 and contained stories, poems, and a one-act play in Swahili. It aims to encourage original writing by East Africans and will be published twice yearly at a subscription rate of $7 \mathrm{~s}$. (\$1.00) per annum (Oxford University Press, East African Branch, P.O. Box 1 2532, Nairobi, Kenya). Contributions in English, Swahili, or any East African language (the latter accompanied by free English translation of the text) should be sent to the Editor, Zuka, P.O. Box 12532, Nairobi. 